\title{
Comparison of patients' and general practitioners' evaluations of general practice care
}

\author{
H P Jung, M Wensing, F Olesen, R Grol
}

Qual Saf Health Care 2002;11:315-319

See end of article for authors' affiliations

\section{Correspondence to:} Dr H P Jung, Veerweg 6, 5851 AP Afferden, The Netherlands;

HPJung@nlzorg.net

Accepted for publication 9 May 2002

\begin{abstract}
Objectives: To compare patients' and general practitioners' (GPs') evaluations of the quality of general practice care.

Design: Written surveys among patients and GPs.

Setting: General practice in the Netherlands.

Subjects: 1772 patients (from 45 GPs) and a random sample of 315 GPs.

Main outcome measures: Patients' and GPs' evaluations of 23 aspects of general practice care and GPs' perceptions of patients' evaluations using a 5 point scale.

Results: The response rate was $88 \%$ in the patient sample and $63 \%$ in the GP sample. The patients' ratings of care were significantly more positive (mean 4.0) than those of the GPs (mean 3.7) as well as GPs' perceptions of patients' evaluations (mean 3.5) ( $p<0.001)$. The overall rank order correlations between the patients' evaluations, GPs' evaluations, and GPs' perceptions of the patients' evaluations were 0.75 or higher $(p<0.001)$. Patients and practitioners gave the most positive evaluations of specific aspects of the doctor-patient relationship ("keeping patients' records and data confidential", "listening to patients", and "making patients feel they had enough time during consultations") and aspects of the organisation of care ("provide quick service for urgent health problems" and "helpfulness of the staff (other than the doctor)"). The aspects of care evaluated least positively by patients as well as by GPs were other organisational aspects ("preparing patients for what to expect from specialist or hospital care" and "getting through to practice on the telephone").

Conclusions: GPs and patients have to some extent a shared perspective on general practice care. However, GPs were more critical about the quality of care than patients and they underestimated how positive patients were about the care they provide. Furthermore, specific aspects of care were evaluated differently, so surveys and other consultations with patients are necessary to integrate their perspective into quality improvement activities.
\end{abstract}

$\mathrm{P}$ ositive patient evaluations of health care are increasingly seen as an important outcome. ${ }^{1}$ Although doubts have been raised as to whether patients have the capacity to evaluate all aspects of care, ${ }^{2}$ patients do, in fact, evaluate their care-for example, in the way they deal with treatment regimens (compliance), ${ }^{3}$ re-attendance, ${ }^{4}$ choice of care provider, ${ }^{5}$ and even health status. ${ }^{6}$ Negative patient evaluations are therefore indicators for potential opportunities to improve the quality of care.

Evaluations by general practitioners (GPs) of the care they provide and their perceptions of the patients' evaluations may be important factors in improving the quality of care. These perceptions are likely to influence their willingness to actually change something in their professional performance or organisation of care. It is unclear how GPs' perceptions relate to patients' evaluations of care. Previous studies have shown a low correlation between patients' and physicians' evaluations and physicians' perceptions of patient evaluations. ${ }^{78}$ Physicians evaluated care less positively than patients, ${ }^{9}{ }^{10}$ and physicians thought that patients would evaluate their care less positively than they actually did. ${ }^{11}$ However, none of these studies was based on a representative sample of patients and physicians. In addition, all studies were in one ${ }^{7-10}$ or two ${ }^{11}$ settings with vocational trainees ${ }^{78}$ and with a small number of patients and physicians. ${ }^{7-10}$ For this reason, a national study of the evaluations of both patients and GPs was undertaken.

The main objective of the study was to compare the views of patients and GPs about general practice care and to find out the extent to which GPs are able to estimate their patients' judgements. If patients and GPs differ considerably in their evaluations of care, they might also differ in those aspects they would like to improve. However, if they agree in their evaluations there is a higher chance that both parties are motivated to improve less positively evaluated aspects of care. If GPs are poor estimators of patients' evaluations and base the selection of topics they want to improve on their perceptions of patients' evaluations, they might choose the wrong ones.

The following research questions were formulated:

- Which aspects of general practice care are evaluated positively or negatively by patients and by GPs, and do these evaluations differ?

- Can GPs adequately estimate their patients' evaluations?

\section{METHODS}

\section{Samples}

The study included a sample of GPs and a sample of patients. The sample of 500 GPs was randomly selected from the national register of GPs maintained by the Netherlands Institute of Primary Care (NIVEL). The GPs were mailed a questionnaire in January 1998 and, after 3 weeks, a reminder was sent to those who had not responded. Each GP also received an invitation to participate in a study in which patients' evaluations would be measured. If they were interested they had to send back a short form in which they had to fill in the location of their practice, type of practice, and age and sex of physician. This form had to be sent back in a different envelope from the anonymous questionnaire. Of those who responded, a stratified sample of 45 GPs from 45 different practices were asked to give a questionnaire to 45 consecutive adult patients visiting their practice after a specific starting point. The practice assistant registered all 
patients visiting the participating doctor after the same starting point in order to make it possible to check if all the questionnaires were handed out consecutively. The 45 practices were selected to obtain a national representative distribution in terms of the following variables: practice location, practice type, age and sex of GP. A total of 2025 questionnaires were handed out in February and March 1998.

The patients could complete the questionnaire at home and return it to the University of Nijmegen in a prestamped envelope. After 3 weeks a reminder was sent to those patients who had not yet responded. The inclusion criteria for the patients were: age 18 or over (in case of children, the questionnaire was given to the accompanying parent), understanding of the Dutch language, and no mental retardation.

\section{Measurement instruments}

The following variables were measured: (1) GPs' evaluations of their own care provision, (2) GPs' perceptions of the patients' evaluations of the care provided, and (3) patients' actual evaluations of the care provided. The selection and formulation of the items for the questionnaire was systematically done to reflect patients' priorities on general practice care. As we were specifically interested in the evaluation of those aspects of general care that appeared to be important for patients, the first step in the process of making a questionnaire to evaluate general practice care was to determine which aspects of care were relevant to patients. Thus, the items were based on (1) a qualitative study of the wishes and expectations of patients and GPs, ${ }^{12}(2)$ a systematic review of the literature and an analysis of 57 studies examining the preferences of patients in primary health care, ${ }^{13}$ and (3) an empirical study of the preferences of patients. ${ }^{14}$ Furthermore, patients' preferences were compared with GPs' preferences. $^{15}$ A preliminary list of 103 aspects of general practice care were selected from these sources. In two consensus meetings of the European Task Force for Patient Evaluation of General Practice (EUROPEP), which includes researchers from eight countries, the preliminary list was reduced to 40 aspects of care. After pilot testing ${ }^{16}{ }^{17}$ and a third consensus meeting, the list was reduced to 23 topics. Items were selected if they were important to patients, had a good item response, gave no translation problems for international comparison, and were discriminative across patients. The items were organised into four dimensions:

- doctor-patient relationship (6 items)

- information and support (4 items)

- medical-technical care (5 items)

- organisation of service (8 items)

These four dimensions were chosen in advance and confirmed by means of factor analysis and reliability analysis. The process of the reduction of the 103 items to 23 items is described in more detail elsewhere. ${ }^{17}$ From this list a questionnaire was developed which was internationally validated and distributed in 10 European countries. ${ }^{18}$

The patients and GPs were asked to score 23 aspects of general practice care on a 5 point Likert scale. They were explicitly asked to evaluate care provided within the past 12 months. The anchors for the scale were $1=$ poor to $5=$ excellent. The GPs' perceptions of their patients' evaluations were also scored in the same manner.

\section{Analysis of data}

The rank orders of the 23 aspects of general practice care within the GP sample and the patient sample were compared using Spearman correlations. The correlations were based on the comparison of the rank orders of items according to the valid percentage of respondents within a sample assessing an item with a score of 4 or 5 on the 5 point Likert scale, which represents a positive evaluation of a particular aspect of gen-
Table 1 Characteristics of GP samples: percentages (absolute numbers)

\begin{tabular}{lccc}
\hline & $\begin{array}{l}\text { Sample of } \\
\text { GPs } \\
(\mathrm{n}=315)\end{array}$ & $\begin{array}{l}\text { Subsample } \\
\text { of GPs } \\
(\mathrm{n}=45)\end{array}$ & $\begin{array}{l}\text { GPs in the } \\
\text { Netherlands } \\
(\mathrm{n}=7093)^{*}\end{array}$ \\
\hline $\begin{array}{l}\text { Sex } \\
\text { Male }\end{array}$ & $83(262)$ & $82(37)$ & $80(5693)$ \\
$\quad$ Female & $17(53)$ & $18(8)$ & $20(1400)$ \\
Age & $4(11)$ & $2(1)$ & $4(264)$ \\
$<35$ years & $38(120)$ & $38(17)$ & $38(2693)$ \\
$35-44$ years & $44(140)$ & $47(21)$ & $47(3310)$ \\
$45-54$ years & $14(44)$ & $13(6)$ & $12(826)$ \\
$55-65$ years & & & \\
Type of practice & $48(147)$ & $44(20)$ & $45(3217)$ \\
$\quad$ Solo practice & $35(114)$ & $31(14)$ & $33(2334)$ \\
Duo practice \\
Group practice & $17(54)$ & $24(11)$ & $22(1542)$ \\
Location of practice & $37(116)$ & $40(18)$ & \\
$\quad$ Rural area & $14(45)$ & $16(7)$ & \\
Small town & $24(75)$ & $22(10)$ & \\
$\quad \begin{array}{l}\text { Provincial city } \\
\text { Large city }\end{array}$ & $25(79)$ & $22(10)$ & \\
\hline
\end{tabular}

No significant difference was seen between either of the GP samples and all Dutch GPs $\left(\chi^{2}\right.$ test, $\left.\mathrm{p}=0.05\right)$

* Source: references 21 and 22. With respect to location of practice, the two samples could not be compared with all Dutch GPs because of the use of different categories.

eral practice care. The mean overall ratings of patients, GPs, and GPs' perception of patients were compared using Student's $t$ tests.

\section{RESULTS}

\section{Characteristics of sample}

Of the 500 GPs who received a questionnaire, 315 returned it (response rate 63\%); almost half of them agreed to take part in the survey. The stratified sample of 45 GPs selected for the survey did not differ from the remaining 270 GPs or national figures with respect to age, sex, type, or location of practice (table 1). There were also no differences between the total GP sample and the national figures (table 1). There were no differences between the subsample of 45 GPs and the remaining 270 GPs with respect to their evaluations of their care and their perceptions of their patients' evaluations. We therefore conclude that the subsample of 45 GPs was similar overall to the total sample.

The demographic data of the patient sample are presented in table 2. The practice assistants of all 45 participating GPs were telephoned to check that the questionnaires had been handed out consecutively. Of the 2025 questionnaires distributed to patients, 1772 were returned (response rate $88 \%$ ). No national figures are available for comparison. Given the high response rate and the stratified sample of practices, however, it can be assumed that the sample is representative of Dutch patients visiting general practice.

\section{How did patients evaluate general practice care?}

Patients evaluated aspects of the doctor-patient relationship most positively. "Keeping your records and data confidential" (rank number 1), "listening to you" (rank number 2), "making you feel you had time during consultations" (rank number 3), and "making it easy for you to tell him or her about your problems" (rank number 8) were evaluated positively by $94.6 \% \quad(n=1440), 88.5 \% \quad(n=1546), 87.8 \%$ $(\mathrm{n}=1540)$, and $82.5 \%(\mathrm{n}=1399)$ of patients, respectively (table $3)$. In addition, aspects concerning information and support"explaining the purpose of tests and treatments" (rank number 6, 83.3\% $(\mathrm{n}=1331))$ and "telling you what you wanted to know about your symptoms and/or illness" (rank number $7,82.7 \%(n=1399))$-and aspects of the organisation 


\begin{tabular}{|c|c|}
\hline \multicolumn{2}{|c|}{$\begin{array}{l}\text { Table } 2 \text { Characteristics of patient } \\
\text { sample }(n=1772) \text { : percentages } \\
\text { (absolute numbers) }\end{array}$} \\
\hline \multicolumn{2}{|l|}{ Sex } \\
\hline $\begin{array}{l}\text { Male } \\
\text { Female }\end{array}$ & $\begin{array}{l}32(570) \\
68(1189)\end{array}$ \\
\hline \multicolumn{2}{|l|}{ Age } \\
\hline $18-24$ years & $6(97)$ \\
\hline $25-44$ years & 40 (713) \\
\hline $45-64$ years & $33(586)$ \\
\hline$>64$ years & $21(368)$ \\
\hline \multicolumn{2}{|l|}{ Education } \\
\hline Low & $48(822)$ \\
\hline Medium & 31 (536) \\
\hline High & 21 (363) \\
\hline \multicolumn{2}{|l|}{ Health status } \\
\hline Excellent & $10(167)$ \\
\hline Very good & $16(284)$ \\
\hline Good & 45 (797) \\
\hline Moderate & $27(470)$ \\
\hline Poor & 2 (39) \\
\hline
\end{tabular}

of care-"providing quick services for urgent health problems" (rank number 4, 85.2\% $(\mathrm{n}=1137)$ ) and "the helpfulness of the staff (other than the doctor)" (rank number 5, 83.8\% $(n=1329))$-were also evaluated very positively. The aspects of care evaluated least positively were organisational aspects"waiting time in waiting room" (rank number 23, 61.2\% $(n=1066))$, "getting through to the practice on the telephone" (rank number 22, 71.3\% $(\mathrm{n}=1247)$ ), "being able to speak to the GP on the telephone" (rank number $21,71.9 \%(n=1051)$ ), and "preparing you what to expect from specialist or hospital care" (rank number 20, 74.7\% $(\mathrm{n}=818)$ ).

\section{How did GPs evaluate general practice care?}

GPs evaluated aspects of the organisation of care most positively. "Provide quick service for urgent health problems" (rank number 1 ) was evaluated positive by $93.9 \%(n=295)$ of GPs and "helpfulness of staff (other than the doctor)" (rank number 3$)$ by $79.2 \%(n=248$, table 3$)$. Aspects of the doctorpatient relationship were also among the most positive evaluated aspects of care. "Keeping patients' records and data confidential" (rank number 2), "listening to patients" (rank number 4), and "making patients feel they had enough time during consultations" (rank number 5) were evaluated positively by $88.9 \%(n=279), 78.1 \%(n=246)$, and $74.0 \%(n=223)$ of GPs, respectively. The aspects of care evaluated least positively were organisational aspects of care, medicaltechnical aspects of care, and aspects related to information and support. The organisational aspects of care were "preparing patients for what to expect from specialist or hospital care" (rank number 23, 40.4\% $(n=127)$ ), "knowing what you had done or told patients during contacts" (rank number 20, 52.7\% $(\mathrm{n}=164)$ ), and "getting through to the practice on the telephone" (rank number 18, $55.1 \%(\mathrm{n}=173))$. The aspects of medical-technical care were "quick relief of patients' symptoms" (rank number 22, $41.4 \%(\mathrm{n}=146))$ and "helping patients to feel well so that they can perform their normal daily activities" (rank number $19,53.8 \%(\mathrm{n}=161))$. The aspects concerning information and support were "helping patients to understand the importance of following your advice" (rank number 21, 47.9\% $(\mathrm{n}=150))$ and "helping patients deal with emotional

Table 3 Patients' and GPs' evaluations of care and GPs' perceptions of patients' evaluations. Rank orders based on valid percentages evaluating positively as 4 or 5 on a 5 point Likert scale

\begin{tabular}{|c|c|c|c|c|c|c|}
\hline \multirow[b]{2}{*}{$\begin{array}{l}\text { What is your opinion of the GP and/or general practice over the last } 12 \\
\text { months with respect to ...* }\end{array}$} & \multicolumn{2}{|c|}{$\begin{array}{l}\text { Patients' evaluations } \\
(n=1772)\end{array}$} & \multicolumn{2}{|c|}{$\begin{array}{l}\text { GPs' evaluations } \\
(n=315)\end{array}$} & \multicolumn{2}{|c|}{$\begin{array}{l}\text { GPs' perceptions of } \\
\text { patients' evaluations } \\
(n=315)\end{array}$} \\
\hline & $\begin{array}{l}\text { Rank no } \\
(\%)\end{array}$ & $\begin{array}{l}\text { Absolute } \\
\text { no }\end{array}$ & $\begin{array}{l}\text { Rank no } \\
(\%)\end{array}$ & $\begin{array}{l}\text { Absolute } \\
\text { no }\end{array}$ & $\begin{array}{l}\text { Rank no } \\
(\%)\end{array}$ & $\begin{array}{l}\text { Absolute } \\
\text { no }\end{array}$ \\
\hline Keeping your records and data confidential? (I)** & $1(94.6)$ & 1440 & $2(88.9)$ & 279 & $1(85.8)$ & 266 \\
\hline Listening to you? (I) & $2(88.5)$ & 1546 & $4(78.1)$ & 246 & $7(60.3)$ & 190 \\
\hline Making you feel you had time during consultations? (I) & $3(87.8)$ & 1540 & $5(74.0)$ & 223 & $12(52.5)$ & 165 \\
\hline Providing quick services for urgent health problems? (IV) & $4(85.2)$ & 1137 & 1 (93.9) & 295 & $2(80.6)$ & 253 \\
\hline Helpfulness of the staff (other than the doctor)? (IV) & $5(83.8)$ & 1329 & $3(79.2)$ & 248 & $4(64.4)$ & 201 \\
\hline Explaining the purpose of tests and treatments? (II) & $6(83.3)$ & 1331 & $11(66.6)$ & 209 & $11(53.0)$ & 166 \\
\hline Telling you what you wanted to know about your symptoms and/or illness? (II) & 7 (82.7) & 1399 & $10(67.2)$ & 211 & $13(50.3)$ & 158 \\
\hline Making it easy for you to tell him or her about your problems? (I) & $8(82.5)$ & 1399 & $13(63.8)$ & 201 & $16(46.8)$ & 147 \\
\hline Physical examination of you? (III) & $9(82.4)$ & 1328 & $6(73.9)$ & 232 & $3(65.8)$ & 206 \\
\hline Interest in your personal situation? (I) & 10 (82.0) & 1409 & $8(70.8)$ & 223 & $8(56.5)$ & 178 \\
\hline Thoroughness? (III) & 11 (81.2) & 1361 & $9(68.4)$ & 214 & $6(61.2)$ & 191 \\
\hline Involving you in decisions about your medical care? (I) & $12(81.0)$ & 1323 & $7(72.7)$ & 229 & $5(61.3)$ & 193 \\
\hline $\begin{array}{l}\text { Helping you to understand the importance of following his or her advice? (II) } \\
\text { Helping you to feel well so that you can perform your normal daily activities? }\end{array}$ & $13(79.7)$ & 1141 & $21(47.9)$ & 150 & $18(36.5)$ & 113 \\
\hline & $14(78.7)$ & 1172 & $19(53.8)$ & 161 & $17(37.9)$ & 113 \\
\hline Getting an appointment to suit you? (IV) & $15(78.1)$ & 1335 & $14(60.8)$ & 191 & $20(34.4)$ & 108 \\
\hline Knowing what s/he had done or told you during contacts? (IV) & $16(76.2)$ & 1135 & $20(52.7)$ & 164 & $10(54.4)$ & 168 \\
\hline $\begin{array}{l}\text { Offering you services for preventing diseases (eg screening, health checks, } \\
\text { immunisations)? (III) }\end{array}$ & 17 (76.1) & 953 & 16 (59.2) & 184 & 9 (54.9) & 168 \\
\hline Helping you deal with emotional problems related to your health status? (III) & 18 (75.5) & 873 & $17(57.6)$ & 181 & $15(47.3)$ & 148 \\
\hline Quick relief of your symptoms? (III) & 19 (74.8) & 1239 & $22(41.4)$ & 126 & $23(24.8)$ & 75 \\
\hline Preparing you for what to expect from specialist or hospital care? (IV) & $20(74.7)$ & 818 & $23(40.4)$ & 127 & $21(31.2)$ & 97 \\
\hline Being able to speak to the GP on the telephone? (IV) & 21 (71.9) & 1051 & $12(65.3)$ & 205 & 19 (34.7) & 109 \\
\hline Getting through to the practice on the phone? (IV) & $22(71.3)$ & 1247 & $18(55.1)$ & 173 & $22(28.3)$ & 89 \\
\hline Waiting time in the waiting room? (IV) & $23(61.2)$ & 1066 & $15(60.5)$ & 190 & $14(48.6)$ & 152 \\
\hline \multicolumn{7}{|c|}{$\begin{array}{l}\text { * Stem in the questionnaire for GPs: "What is your own opinion of yourself and/or your general practice over the last } 12 \text { months with respect to ...." and } \\
\text { "What is your perception of the opinion of your patients of you and/or your general practice over the last } 12 \text { months with respect to ...". The word "you" } \\
\text { was replaced by "patients" in all } 23 \text { items for general practitioners, e.g. "making patients feel they had time during consultations", so the words "him or } \\
\text { her", "s/he", "his or her" were replaced by "you" or "your". } \\
\text { * "Dimensions of general practice care: I=doctor-patient relationship (6 items); Il=information and support (4 items); IIl=medical-technical care (5 items); } \\
\text { IV=organisation of services (8 items). }\end{array}$} \\
\hline
\end{tabular}


problems related to their health status" (rank number 17, $57.6 \%(\mathrm{n}=181))$.

\section{Did patients' and GPs' evaluations differ?}

The absolute ratings differed systematically between the patients and the GPs. The patient sample had a mean overall rating of 4.0, while the GP sample had a mean overall rating of 3.7 (own evaluations) and 3.5 (perception of patients' evaluations) $(\mathrm{p}<0.001)$. GPs were thus more critical of their care than patients and underestimated just how positive patients actually were about the care they provided.

The Spearman rank order correlation between the patients' and the GPs' evaluations was $0.76(\mathrm{p}<0.001)$-that is, the rank orders for the 23 different aspects of general practice care were very similar. The five aspects ranked highest (most positively) by the patients were also ranked highest by the GPs: "keep data confidential", "listen to you", "enough time during consultation", "provide quick service for urgent problems", and "helpfulness of staff".

However, there were also some differences in rank order of evaluations. The largest differences were found for the organisational aspects "waiting time in the waiting room" and "being able to speak to the GP on the telephone". GPs ranked these aspects 12 and 9 places higher, respectively, than patients. However, the patients' ranking of the aspect related to information and support ("helping to understand the importance of following advice") was 8 places higher than GPs' ranking.

When looking at absolute percentages of positive evaluations (ratings), patients and GPs differed substantially. The largest differences were found for the organisational aspect "preparing for what to expect from specialist or hospital care" (rated positive by $74.7 \%(\mathrm{n}=818)$ of patients and by only $40.4 \%(\mathrm{n}=127)$ of GPs $)$, the medical-technical aspect of care "quick relief of symptoms" $(74.8 \%(n=1239)$ of patients, $41.4 \%(n=126)$ of GPs), and for the aspect related to information and support "helping to understand the importance of following the GPs' advice" $(79.7 \% \quad(n=1141)$ of patients, $47.9 \%(n=150)$ of GPs $)$.

\section{How did GPs perceive patients' evaluations?}

The Spearman rank order correlation between the patients' and the GPs' perceptions of the patients' evaluations was 0.75 $(\mathrm{p}<0.001)$ - that is, these two rank orders for the 23 different aspects of general practice care were also very similar. Four of the five aspects ranked lowest by the patients were also ranked lowest by the GPs when asked about their perceptions of their patients' evaluations: "quick relief of symptoms", "prepares you for what to expect from hospital care", "able to speak to GP on telephone", and "getting through to practice on the telephone".

The greatest differences in rank order of evaluations were found for the aspects of the doctor-patient relationship "making the patient feel s/he had enough time during consultation" and "making it easy for patients to tell you about their problems". Patients' rankings of these aspects were 9 and 8 places higher, respectively, than the ranking of GPs' perceptions of these evaluations. Patients' rankings of the organisational aspect "waiting time in the waiting room" and the medicaltechnical aspect "offering the patient services for preventing diseases (eg screening, health checks, immunisations)" were 9 and 8 places lower, respectively, than the rankings of GPs' perceptions of these evaluations.

However, when looking at absolute percentages of positive evaluations (ratings), patients and GPs' perceptions of patients differed substantially. The greatest differences were found for the medical-technical aspect of care "quick relief of patients' symptoms" (rated positive by 74.8\% $(n=1239)$ of patients while only $24.8 \%(n=75)$ of GPs thought this would be rated positive by patients) and the organisational aspects "getting an appointment to suit you" $(78.1 \%(n=1335)$ of patients, 34.4\% $(\mathrm{n}=108)$ of GPs' perceptions) and "preparing patients for what to expect from specialist or hospital care" $(74.7 \%(n=818)$ of patients, $31.2 \%(n=97)$ of GPs' perceptions).

\section{DISCUSSION}

GPs were more critical about the care they provided than patients and GPs underestimated how positive patients actually were about general practice care. However, patients' and GPs' views on what was relatively best or worst in general practice care were remarkably similar. Both patients and GPs evaluated the doctor-patient relationship and the organisational aspects "providing quick services for urgent health problems" and "helpfulness of staff" most positively. The other organisational aspects were among the least evaluated aspects of care.

This study has some limitations. Despite the stratified sampling procedure, the 45 GPs who handed out the questionnaires may not be representative of the total group of GPs. It is, however, reassuring that there was no difference between the 45 GPs and the remaining GPs with respect to their evaluations of the care provided or their estimations of patients' evaluations of care. Furthermore, almost half the GPs worked in solo practices. This might limit the generalisability of the results to other healthcare settings such as in the UK. However, the results of a consultation related study in the UK which compared patients' and doctors' satisfaction in a group practice of five GPs were remarkably similar to our findings. ${ }^{10}$

The differences between the ranking and ratings between the different groups are difficult to interpret. For example, the aspect "getting an appointment to suit you" was ranked almost as high (15th) for patients as for GPs (14th). However, the percentage of GPs who rated this aspect positively was $61 \%$, which is as low as the lowest ranked item for patients (waiting time). Similarly, the aspect "getting through to the practice on the telephone" was ranked higher for GPs (18th) than for patients (22nd). However, the percentage of GPs who rated this aspect positively was $55 \%$, which is lower than the rating of patients $(71 \%)$ and even lower than the lowest ranked item for patients (waiting time 61\%). It is unclear whether these figures reflect answering tendencies (GPs were more critical than patients), sampling variability, or real differences in opinions. It should be kept in mind that there is only a $10 \%$ difference between the items ranked 4 th and 20 th in the patient sample, so there is considerable scope for sampling variability.

If the results of the rankings and ratings are combined, the following picture emerges. Aspects of the doctor-patient relationship and provision of information were rated and ranked higher by patients than by GPs. This includes the aspects "listening to patients", "making patients feel they had time during consultations", "explaining the purpose of tests and treatments", "telling patients what they wanted to know about their symptoms and/or illness", "making it easy for patients to talk about their problems", and "helping patients to understand the importance of following advice". This has also been found in other studies. ${ }^{10}$ Furthermore, the two medicaltechnical aspects "helping the patient to feel well so that patients can perform their normal daily activities" and "quick relief of patients' symptoms" were rated and ranked higher by patients than GPs' ratings and ranking and GPs' perception about patients" rating and ranking. Only the aspect "providing quick services for urgent health problems" was rated and ranked higher by GPs than by patients. GPs and patients may have different ideas about what is an urgent health problem.

Viewed from the patients' perspective, those aspects of care least positively evaluated are potential candidates for improvement, as all aspects of care included in the EUROPEP questionnaire reflect patients' priorities. GPs must therefore 


\section{Key messages}

- Patients' and GPs' views on what is best and what is worst about general practice care are remarkably similar.

- GPs are more critical about care provision than patients.

- GPs underestimate just how positive patients are about the care provided.

- Patients and GPs can be partners in selecting topics for quality improvement.

be prepared to focus on these aspects of care as indicators of potential opportunities for improvement. ${ }^{19}$ The GPs' own evaluations of the care they provide and their perceptions of their patients' evaluations may influence their intention to change something. ${ }^{20}$

It is reassuring to see that patients and GPs generally have a shared view of what constitutes good or optimal care and what aspects of care may be less than optimal. On the other hand, patients had slightly different opinions from GPs about specific areas, so it is dangerous to assume that patients' views on the quality of care can be predicted on the basis of GPs' perceptions of patients' evaluations alone. Furthermore, subgroups of patients such as those from ethnic minorities and young mothers may have different views on general practice care, so it is important for GPs to listen to individual patients and to subgroups of patients.

We believe that patients and GPs should be partners in the selection of topics for quality improvement. This study in patients and GPs in the Netherlands suggests that aspects of the organisation of general practice in particular need further attention. The aspects "preparing for what to expect from specialist or hospital care" and "getting through to the practice on the telephone" were rated and ranked rather poorly by both patients and GPs and may therefore be good topics for quality improvement.

\section{Authors' affiliations}

H P Jung, M Wensing, R Grol, Centre for Quality of Care Research, University of Nijmegen and University of Maastricht, The Netherlands F Olesen, Research Unit for General Practice, University of Aarhus, Denmark

\section{REFERENCES}

1 Richards T. Patients' priorities. Need to be assessed properly and taken into account. BN 1999;318:277.
2 Williams B. Patient satisfaction: a valid concept? Soc Sci Med 1994;38:509-16.

3 Vuori H. Patient satisfaction-does it matter? Qual Assurance Health Care $1991 ; 3: 183-9$

4 Scott A, Smith R. Keeping the customer satisfied: issues in the interpretation and use of patient satisfaction surveys. Int I Qual Health Care 1995;6:353-9.

5 Weiss B, Senf J. Patient satisfaction survey instrument for use in health maintenance organisations. Med Care 1990;28:434-45.

6 Kaplan SH, Ware JE. The patient's role in health care and quality assessment. In: Goldfield N, Nash DB, eds. Providing quality care, the challenge to physicians. Philadelphia, Pennsylvania: American College of Physicians, 1989

7 Merkel WT. Physician perception of patient satisfaction. Med Care 1984;22:453-9.

8 DiMatteo MR, DiNicola DD. Sources of assessment of physician performance: a study of comparative reliability and patterns of intercorrelation. Med Care 1981;19:829-42.

9 Pascoe GC, Attkisson CC. The evaluation ranking scale. A new methodology for assessing satisfaction. Eval Program Planning 1983;6:335-47.

10 Rashid A, Forman W, Jagger C, et al. Consultation in general practice: a comparison of patients' and doctors' satisfaction. BM 1989:299:1015-6.

11 Hilton TF, Butler MC, Nice DS. Patient and provider satisfaction in navy family practice and non-family practice clinics. J Fam Pract 1984:18:569-73

12 Wensing $M$, Grol R, Van Montfort $P$, et al. Indicators of the quality of general practice care of patients with chronic illness: a step towards real involvement of patients in the assessment of the quality of care. Qual Health Care 1996:5:73-80.

13 Wensing $M$, Jung HP, Mainz J, et al. Which aspects of care are important for patients? A systematic literature review. Soc Sci Med 1998;47:1573-88.

14 Grol R, Wensing M, Mainz J, et al. Patients' priorities with respect to general practice care: an international comparison. Fam Pract 1999; 16:4-11

15 Jung HP, Wensing M, Grol R. What makes a good general practitioner: do patients and doctors have different views? Br J Gen Pract 1997:47:805-9.

16 Jung HP, Van Horne F, Wensing M, et al. Which aspects of general practitioners' behaviour determine patients' evaluations of care? Soc Sci Med 1998:47:1077-87.

17 Wensing M, Mainz J, Grol R. A standardized and validated instrument for patient evaluations of general practice care. Eur J Gen Pract 2000;6:82-7

18 Grol R, Wensing M, Mainz J, et al. Patients in Europe evaluate general practice care: an international comparison. Br J Gen Pract 2000;50:882-7.

19 Solberg LI, Mosser G, McDonald S. The three faces of performance measurement: improvement, accountability, and research. Jt Comm J Qual Improv 1997;23:135-47.

20 Berwick DM. Heal thyself or heal thy system: can doctors help to improve medical care? Qual Health Care 1992;1(Suppl): s2-8.

21 Hingstman L. Demographic information about GPs in the Netherlands (in Dutch). Utrecht: NIVEL (Netherlands Institute of Primary Care), 1999.

22 Hingstman L, Kenens R, Van der Windt W, et al. Report care and welfare job market 2001 (in Dutch). Tilburg: OSA Tilburg, 2001. 